\title{
Efficient Control of Sensorless Hybrid Electric Vehicle Using RBFN Controller
}

\author{
Srikanth RAVIPATI ${ }^{\mathbf{1}}$, Venkatesan MANI ${ }^{2 *}$, Srinivasa Rao YARLAGADDA ${ }^{\mathbf{1}}$ \\ ${ }^{1}$ Vignan's Foundation for Science, Technology \& Research, Andhra Pradesh, India \\ ravipatister@gmail.com, cnuiitr@gmail.com \\ 2 Vignan's Lara Institute of Technology \& Science, Andhra Pradesh, India \\ venkatesangct@gmail.com (*Corresponding Author)
}

\begin{abstract}
In this paper, a Radial Basis Function Network (RBFN) controlled Sensorless Hybrid Electric Vehicle (HEV) using a Brushless DC Motor (BLDC) is presented. In this context, hybrid energy sources (Photovoltaic\& Fuel cell) are designed for supplying electrical energy to the HEV. This involves the design of a Maximum Power Point Tracking (MPPT) system using a Fuzzy Logic controller (FLC) in order to track the maximum power obtained from hybrid energy sources under various weather conditions. The speed of HEV drives is efficiently controlled by using the RBFN-ANN controller in comparison with sensor based control techniques. The performance of the proposed HEV was tested for two types of controllers, namely the Proportional Integral (PI) and the RBFN-ANN controller. The performance of the system is analysed with respect to the three different load torque conditions. The performance comparison is made in terms of generated torque ripple and speed response. The proposed hybrid electric vehicle using a RBFN-ANN controller is validated through the MATLAB/Simulink environment.
\end{abstract}

Keywords: RBFN, HEV, Photovoltaic, Fuel cell, FLC MPPT, Sensorless, Speed and Torque ripple.

\section{Introduction}

The present society is heavily affected by the greenhouse effects due to the emission of a huge amount of $\mathrm{CO}_{2}$ from the fossil fuel based conventional vehicles (Kawamoto et al., 2019). It is necessary to reduce the utilization of automotive vehicles in order to protect the life of earth and human life for the coming years (Pradeep et al., 2021). The solar PV energy is ahead of the numerous types of renewable energy sources (RES) with respect to the reduced noise pollution and production of clean energy (Tawalbeh et al., 2021). Furthermore, in addition to solar PV energy, fuel cells are also one of the most advantageous sources of electricity.

Tracking the power from the solar panel is very difficult with variable irradiance and nonlinear loading conditions (Zandi \& Mazinan, 2019). To track the maximum power from the solar PV panel with variable irradiance and loading conditions, a different MPPT algorithms are investigated by the researchers (Zarrad et al., 2019). Among the different MPPT algorithms, a Fuzzy Logic Controller (FLC) is chosen to track maximum power from the solar panel (Parvaneh \& Khorasani, 2020). It has several advantages like cost-effectiveness of implementation, covering a wide range of operating conditions, robust operation, increased reliability, and higher precision with a huge number of membership functions. The controlled output from the MPPT based distributed renewable system will be directed to brushless DC motor (BLDC) through an inverter for driving the vehicle (Darcy Gnana Jegha et al., 2020). The conventional DC motors can be used for driving the vehicle which is highly efficient but the main drawback of these motors lies in a requirement of commutator and brushes which are very high maintenance. To avoid the problems with the commutator and brushes such as sparking, a BLDC motor has been introduced (Kommula \& Kota, 2020). The current in all phases of the motor is rectangular and synchronized with the back electromotive force (EMF), generating constant torque at a constant speed. This motor will be controlled with an inverter requiring a sensor for sensing rotor position for starting and also for providing a certain commutation sequence to the inverter (Gamazo-Real et al., 2010). The controlling of the inverter will be done in two ways namely in sensor mode and sensorless mode. Sensorless control accomplishes the zero-crossing detection to determine the position of the rotor. In this control, only two windings are excited and the third winding is floated. To determine the zerocrossing time of EMF, a voltage of the floating winding with respect to the neutral point has to be determined. From the motor, using zero-crossing detection sensed position will be decoded and then sent to the hall signal controller. This sensorless control involves certain advantages like the elimination of sensor cost, reduced ripples in the torque, and an increase in the power capability. Also to improve the performance of 
the BLDC motor, the sensorless speed controller has been investigated (He, Zheng \& Fang, 2017). Based on the literature review, the various types of AC and DC motors are used for the electrical vehicle applications such as conventional DC motor, Induction motor and Permanent magnet synchronous motor. Among the various types of electric motors, BLDC motor is extensively used in electrical vehicles due to its characteristics. They are high power density, high efficiency, wide speed range, less maintenance, good dynamic response. The BLDC motor will be controlled with inverter requiring sensors for sensing rotor position for starting and also for providing a certain commutation sequence. In recent years, authors have been focused on sensorless control of BLDC motor for electrical vehicles incorporated with different controllers (Ramírez-Cárdenas \& Trujillo-Romero, 2020). The conventional proportional integral (PI) controller and Proportional Integral Derivative (PID) are most commonly used for controlling BLDC motor. In order to overcome the saturation effect of conventional PI controller, Anti-windup PI controller has been applied to the sensorless BLDC motor. A Fuzzy logic based controller was applied for the controlling of speed of the sensorless BLDC motor and Fuzzy-PI controller is designed for the handling of the non-linear characteristics of BLDC motor. Furthermore,
Fuzzy-PID and Model reference adaptive control based systems based on BLDC motor drive are discussed in (El-Samahy \& Shamseldin, 2018). BLDC motor has highly nonlinear characteristics, therefore modelling of mathematical expressions for the conventional controller is very difficult. Hence, RBFN-ANN based controller is designed for HEVs. The simulation results and performance are validated by using MATLAB/ Simulink environment.

The rest of this paper is structured as follows. Section 2 presents the sensorless controlled HEV and Section 3 sets forth the P\&O-FLC based MPPT control. The proposed RBFN-ANN is described in Section 4. Simulation results and comparative analysis of the proposed system are discussed in Section 5. Finally, Section 6 includes the conclusion of this paper.

\section{Proposed System Design}

The block diagram for the proposed sensorless speed control-based electric vehicle is shown in Figure 1. It consists of solar panel, fuel cell, high gain interleaved boost converter, $\mathrm{P} \& \mathrm{O}-\mathrm{FLC}$ based MPPT system, sensorless speed control strategy with PI controller and RBFN-ANN controller, three-phase inverter, and BLDC motor. The integrated output from the system consisting of

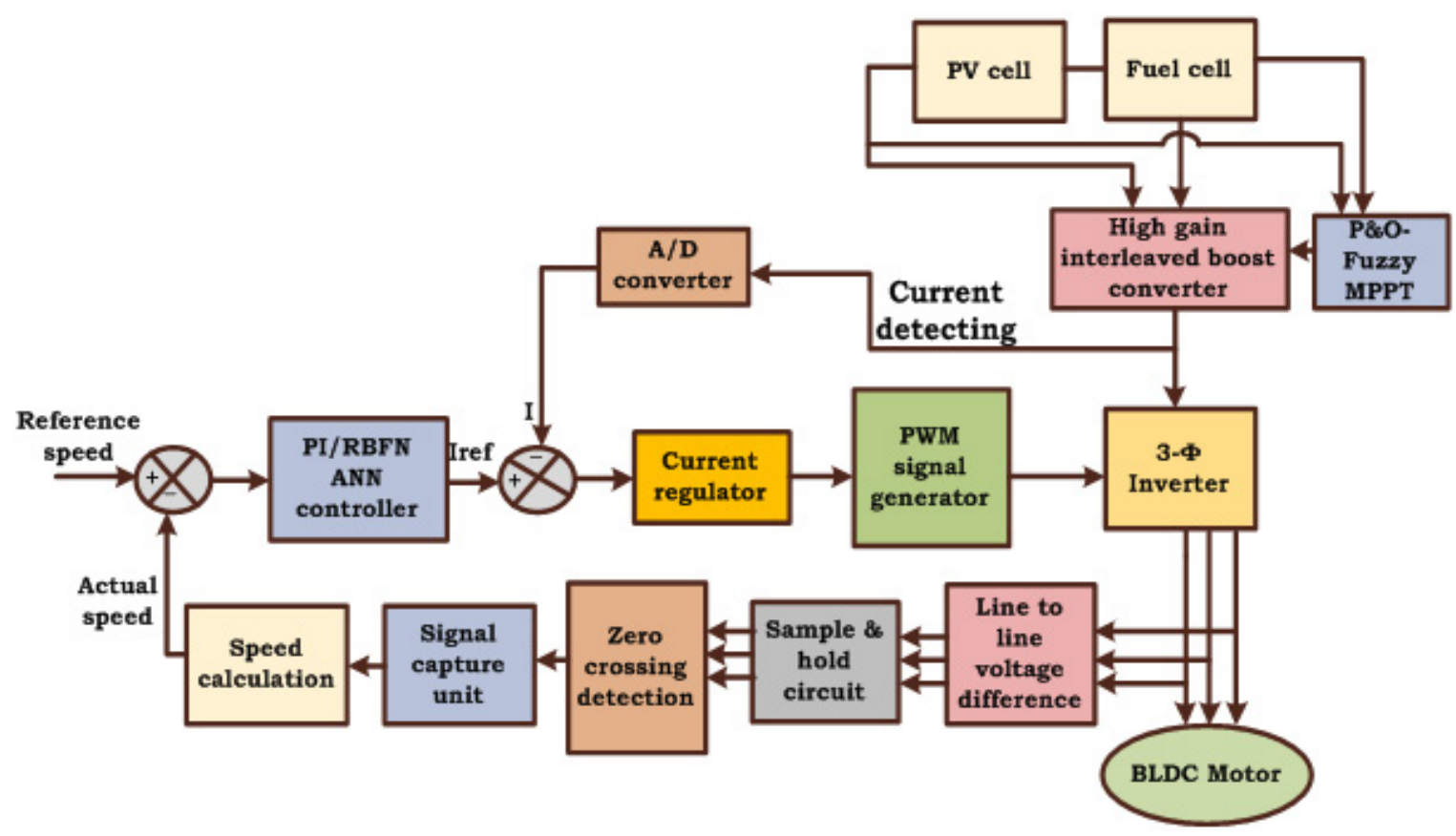

Figure 1. Sensorless controlled HEV using RBFN-ANN (Jyotheeswara Reddy \& Sudhakar, 2018)

https://www.sic.ici.ro 
a solar panel and a fuel cell is directed to the High Gain Interleaved (HGI) boost converter with the falling of irradiance onto the solar panel and inflow of hydrogen into a fuel cell. The HGI boost converter converts the low voltage from the integrated system into high rated voltage with a lower duty cycle attaining gate pulse from the MPPT controller.

\subsection{HGI Boost Converter}

The HGI boost converter consists of three switches (S1, S2 \& S3), three diodes (D1, D2 \& D3) for freewheeling operation, three filter inductors (L1, L2 \& L3) and three filter capacitors (C1, C2 \& C3) and it is illustrated in Figure 2 (Jyotheeswara Reddy \& Sudhakar, 2018). The converter is assumed to be operated in continuous conduction mode with switching operation using $180^{\circ}$ phase shift. The proposed HEV system is modified based on the work of Jyotheeswara Reddy \& Sudhakar (2018) and Srikanth et al. (2020).

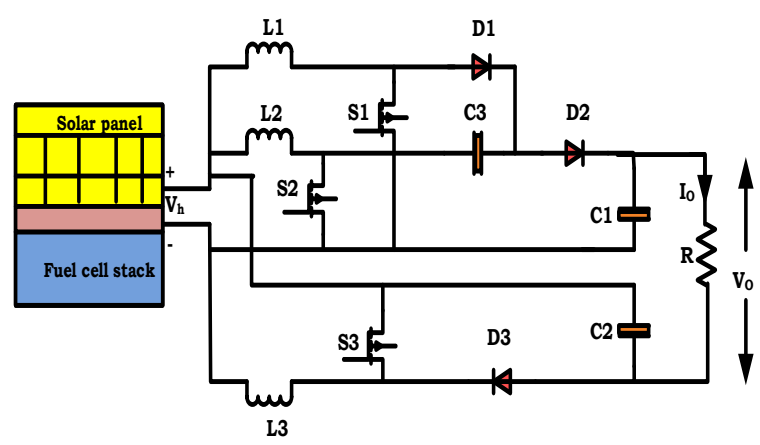

Figure 2. HGI boost converter (Srikanth et al., 2020)

The expression for the capacitor at the input side can be given as:

$$
C_{3}=\frac{V_{0}}{R \Delta V f_{s}}
$$

where $V_{0}$ is the output voltage, $R$ is the load resistance, $\Delta V$ is the ripple voltage of the capacitor and $f_{s}$ is the switching frequency of the converter.

The expression for the capacitors on the output side can be given as:

$C_{1}=C_{2}=\frac{D V_{0}}{R \Delta V f_{s}}$

The expression for the filter inductances can be given as:
$L_{1}=L_{2}=L_{3}=\frac{D V_{h}}{\Delta I f_{s}}$

where $\Delta I$ is the ripple current of the inductor, $V_{h}$ is the output voltage of the hybrid energy system and $I_{0}$ is the load current.

The expression for duty ratio can be specified as:

$D=\frac{V_{o}-2 V_{h}}{V_{o}+V_{h}}$

\subsection{Sensorless BLDC motor control}

The BLDC possesses a simple structure, higher operating efficiency, longer life due to the absence of sliding contacts, higher reliability, and reduction of electromagnetic interference. Furthermore, the motor is efficiently controlled by electronic commutation techniques. They have the advantages of superior speed-torque characteristics with higher efficiency and increased dynamic performance when compared to brushed motors thereby delivering greater torque. The equivalent circuit of the BLDC motor is shown in Figure 3. The BLDC motor can be modeled as a 3-phase 4-pole machine with a stator fed by a three-phase inverter.

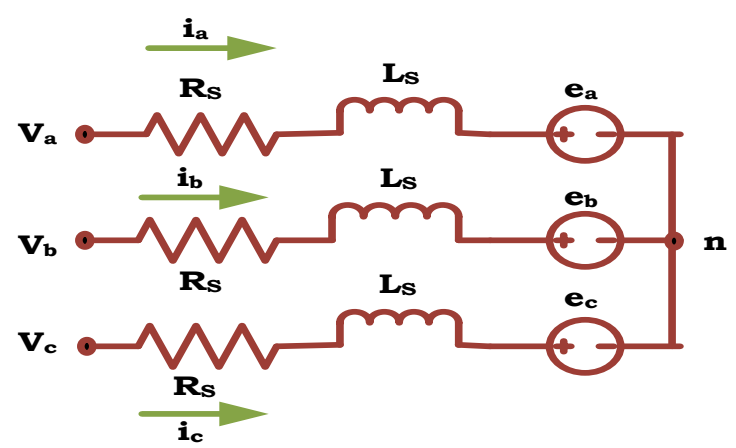

Figure 3. Equivalent circuit of BLDC motor

From Figure 3, $\mathrm{V}_{\mathrm{a}}, \mathrm{V}_{\mathrm{b}}, \mathrm{V}_{\mathrm{c}}$ are the stator phase voltages and $i_{a}, i_{b}, i_{c}$ are stator phase currents, $R_{s}$ is stator resistance, $\mathrm{L}_{\mathrm{S}}$ is stator inductance and $\mathrm{e}_{\mathrm{a}}, \mathrm{e}_{\mathrm{b}}, \mathrm{e}_{\mathrm{c}}$ are back EMFs. The expression for the voltages across the windings of the motor can be given as:

$\left[\begin{array}{l}V_{a} \\ V_{b} \\ V_{c}\end{array}\right]=\left[\begin{array}{ccc}R_{s} & 0 & 0 \\ 0 & R_{s} & 0 \\ 0 & 0 & R_{s}\end{array}\right]\left[\begin{array}{l}i_{a} \\ i_{b} \\ i_{c}\end{array}\right]+\frac{d}{d t}\left[\begin{array}{ccc}L_{s} & 0 & 0 \\ 0 & L_{s} & 0 \\ 0 & 0 & L_{s}\end{array}\right]\left[\begin{array}{l}i_{a} \\ i_{b} \\ i_{c}\end{array}\right]+\left[\begin{array}{c}e_{a} \\ e_{b} \\ e_{c}\end{array}\right]$ 
The expression for the electromotive force can be given as:

$$
E=\frac{k}{p}\left[\begin{array}{c}
\sin \theta_{e} \\
\sin \left(\theta_{e}-\frac{2 \Pi}{3}\right) \\
\sin \left(\theta_{e}-\frac{4 \Pi}{3}\right)
\end{array}\right] \frac{d \theta_{e}}{d t}
$$

where $\mathrm{k}$ is motor voltage constant, $\mathrm{p}$ is the number of poles, $\theta_{e}$ electromotive angle $\frac{d \theta_{e}}{d t}$ electromotive speed.

The expression for the rotor angle can be given as:

$\theta_{e}=\frac{p}{2 \theta_{m}}$

where $\theta_{m}$ is the mechanical rotor angle $\frac{d \theta_{m}}{d t}$,
mechanical rotor speed

The expression for electromagnetic torque can be given as:

$T_{e}=\frac{\left(e_{a} i_{a}+e_{b} i_{b}+e_{c} i_{c}\right)}{\omega}$

where $\omega$ is the angular velocity.

The expression for mechanical torque that can be transferred to the shaft of the motor can be given as:

$T_{e}-T_{l}=J \frac{d \omega}{d t}+B \omega$

where $T_{e}$ is the electromagnetic torque, $T_{l}$ is the load torque, $J$ is the moment of inertia, $d \omega$ is the change in the angular velocity and $B$ is damping coefficient. BLDC motors are driven by the DC voltage obtained from the inverter with current commutation being controlled by power semiconductor devices. In general, the instants of commutation will be determined by the sensor at the rotor position but the proposed control technique eliminates the use of sensors. So, to obtain the speed and to control the switching states, sensorless control is proposed which works with the help of zero-crossing detection (Jafarboland \& Silabi, 2019). The proposed sensorless control uses two loops with an outer speed loop and an inner current loop. The outer speed loop utilizes zero-crossing detection for attaining the speed of the motor in sensorless control techniques. Then the actual speed obtained from the ZCD will be compared with the reference speed and then fed to the controller finding the reference current. The actual current of the motor will be compared with the reference current in the inner current loop generating processed error with the controller. Then the processed error will be used for generating gate signals for the inverter.

\subsection{Zero-crossing Detection}

Zero crossing detection determines the position of the rotor with two excited windings and third winding is floated condition. To attain the zerocrossing time of back EMF, a terminal voltage to a neutral point of the floating winding will be determined. The output line voltages from the inverter will be fed to the line to line voltage difference block which determines the difference between line voltages of the three phases and then the differences being sent to the sample and hold circuit. The sample and hold circuit samples the line voltage differences between phases and the samples will be sent to zero-crossing detection block. The ZCD block determines the zero crossings of the samples during negative and positive zero crossings (Park et al., 2019). It is shown in Figure 4.

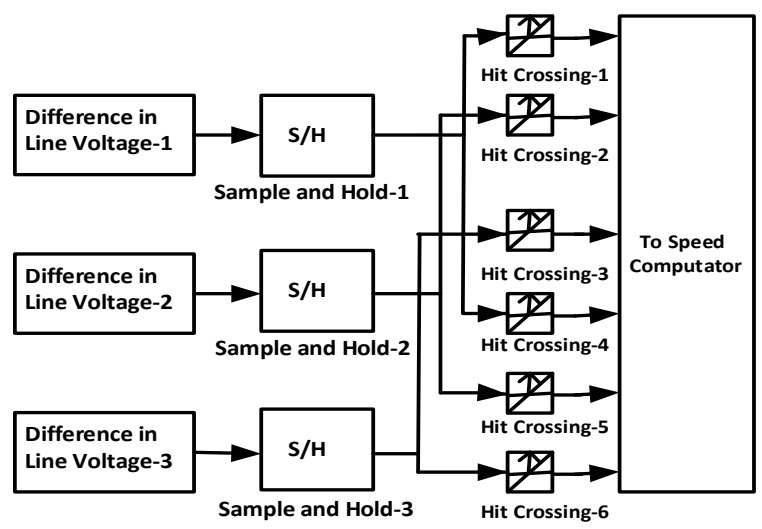

Figure 4. Internal circuit of the zero-crossing detection

The phase to neutral voltages can be expressed as:

$$
\begin{aligned}
& V_{a n}=i_{a} R_{s}+L_{s} \frac{d i_{a}}{d t}+e_{a n} \\
& V_{b n}=i_{b} R_{s}+L_{s} \frac{d i_{b}}{d t}+e_{b n} \\
& V_{c n}=i_{c} R_{s}+L_{s} \frac{d i_{c}}{d t}+e_{c n}
\end{aligned}
$$


The expression for the line voltage between phase ' $a$ ' and phase ' $b$ ' can be given as

$V_{a b}=V_{a n}-V_{b n}$

$V_{a b}=R_{s}\left(i_{a}-i_{b}\right)+L_{s} \frac{d\left(i_{a}-i_{b}\right)}{d t}+e_{a n}-e_{b n}$

The expression for the line voltage between phase ' $b$ ' and phase ' $c$ ' can be given as:

$V_{b c}=V_{b n}-V_{c n}$

$V_{b c}=R_{s}\left(i_{b}-i_{c}\right)+L_{s} \frac{d\left(i_{b}-i_{c}\right)}{d t}+e_{b n}-e_{c n}$

The expression for the line voltage between phase 'c' and phase ' $a$ ' can be given as:

$V_{c a}=V_{c n}-V_{a n}$

$V_{c a}=R_{s}\left(i_{c}-i_{a}\right)+L_{s} \frac{d\left(i_{c}-i_{a}\right)}{d t}+e_{c n}-e_{a n}$

The expression for difference in the line voltage can be given as:

$V_{a b b c}=V_{a b}-V_{b c}$

$V_{a b b c}=R_{s}\left(i_{a}-2 i_{b}+i_{c}\right)+L_{s} \frac{d\left(i_{a}-2 i_{b}+i_{c}\right)}{d t}+e_{a n}-2 e_{b n}+e_{c n}$

One considers the condition of the floated terminal so that phase $\mathrm{B}$ is in open:

$i_{a}=-i_{c}$

$i_{b}=0$

Then the difference in line voltage can be rewritten as:

$$
\begin{aligned}
& V_{a b b c}=e_{a n}-2 e_{b n}+e_{c n} \\
& V_{a b b c}=-2 e_{b n}
\end{aligned}
$$

From the equations (10) to (24), it can be shown that phase $\mathrm{B}$ changes from one polarity to another polarity thereby enabling zero crossings.

Similarly, all the other phases change their polarity enabling zero crossings. The speed computation block is shown in Figure 5. From the zero-crossing detectors, the decoding will be done with logical operations thereby attaining three decoding signals. From the decoding signals using the period, the frequency of the signal will be calculated. Using the synchronous speed concept with several poles and the obtained frequency, speed will be determined. The actual speed of the motor calculated from the zero-crossing detection will be compared with the reference speed. The error will be fed to the controller which processes the error and determines the reference current. The reference current calculated from the outer speed loop will be compared with the actual currents from the inverter generating the error. The error will be fed to PI and RBFN-ANN controller which reduces the error.

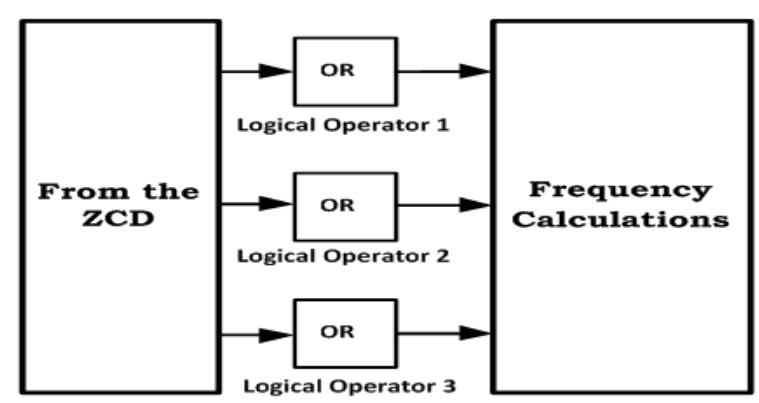

Figure 5. Internal circuit of speed computation block

\subsection{PWM Signal Generator}

The three signals obtained from the EMF computation block will be used to generate the gate pulses for inverter switches. The phase ' $a$ ' signal will be compared with zero generating gate signals for switches $\mathrm{S} 1$ and $\mathrm{S} 2$. Then the phase ' $\mathrm{b}$ ' signal will be compared with zero generating gate signals for switches S3 and S4. Similarly, phase 'c' signal will be compared with zero generating gate signals for switches S5 and S6. Thus, one achieves thereby achieving three levels at the output of the inverter with three phases. The inverter commutation is derived from Figure 6.

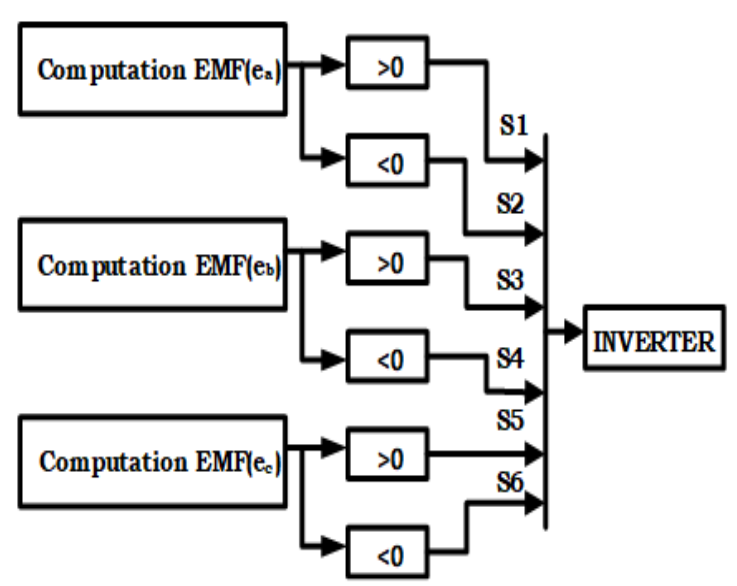

Figure 6. PWM generation logic 


\section{P\&O-FLC Based MPPT Control}

\subsection{Perturb and Observe MPPT}

As the source of the solar power system is the sun whose intensity varies for 24 hours, the output of the solar power system is also not constant. Also, there will be only one maximum power at the rated irradiance and it is required to attain maximum power in order to reach a maximum efficiency of the system. This can be only achieved with the help of a tracking system known as the maximum power point tracking system which operates the solar power system at the maximum operating point. Figure 7 shows the MPPT tracking system with a FLC.

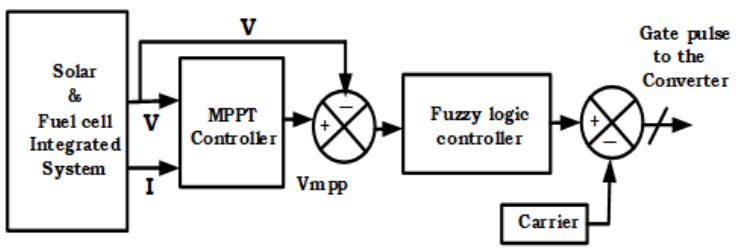

Figure 7. Block diagram of the P\&O FLC-MPPT technique

The DC output voltage and current obtained from the solar-fuel cell integrated system will be directed to the maximum power point tracking system producing maximum power point voltage as the output of the maximum power point tracking system with certain perturbation. The maximum power point voltage will be compared with the actual output of the hybrid system which generates the error. The error between the maximum power point voltage and the actual output of the hybrid system will be sent to the fuzzy logic controller for the processing of error. The processed error from the controller will be compared with the carrier waveform to generate gating pulses for the switches of the high gain interleaved boost converter.

\section{Proposed RBFN-ANN Controller}

Radial basis function neural network is a type of feed-forward neural network using Gaussian activation functions. They can be applied in function and pattern approximations due to their excellent approximation capabilities, faster training algorithms, and simpler network structure. It consists of an input layer with input neurons, a hidden layer with non-linear activation functions, and output layer which computes outputs. The hidden layer uses a group of basis function units that performs the nonlinear transformation from the input layer to the hidden layer. So the passage of information from the input layer to the hidden layer is nonlinear and from the hidden layer to the output layer it is linear. The RBFN-ANN control architecture is shown in Figure 8.

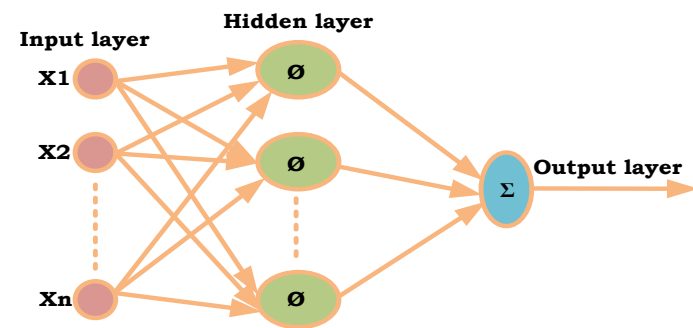

Figure 8. RBFN-ANN control architecture

The expression for the output of $j^{\text {th }}$ neuron in the hidden layer can be given as:

$Y_{j}=K\left(\frac{\left\|x-\mu_{j}\right\|}{\sigma_{j}^{2}}\right)$

where the constant $\mathrm{K}$ is a symmetrical function that changes from the center of the neurons to zero $^{\text {th }}$ position rapidly. $u_{j}$ is the mean of $j^{\text {th }}$ neuron, $\sigma_{\mathrm{j}}$ is standard deviation of $\mathrm{j}^{\text {th }}$ neuron. The above expression indicates that $Y_{j}$ has the desired value only if the distance $\left\|x-\mu_{j}\right\|$ is smaller than $\sigma_{j}$. The output from the $\mathrm{m}^{\text {th }}$ neuron in the output layer can be given as:

$Z_{i}=\sum W_{i j} Y_{j}$

where $W_{i j}$ represents the hidden-output layer weights.

\subsection{Procedure for the Training of RBFN Network}

Radial basis function neural network undergoes training at both the hidden layer and also at the output layer. In general, the hidden layer undergoes unsupervised learning and the output layer undergoes supervised learning with the respective target output. The steps involved in training the radial basis function neural network are given below (Meng et al., 2017).

Step 1: All the weights between the input layer and hidden layer will be initialized at smaller random values. 
Step 2: Apply inputs at the input layer and perform radial basis function computation at the hidden layer.

Step 3: Select the centers for the radial basis function from the set of input variables. Do the computation at the output of the hidden layer using the expression below.

$Y_{j}=K\left(\frac{\left\|x-\mu_{j}\right\|}{\sigma_{j}^{2}}\right)$

Step 4: All the weights between the hidden layer and output layer will be initialized at smaller random values and the outputs from the hidden layer will be fed to the output layer as inputs.

Step 5: The computation at the output of the output layer using the below expression.

$$
Z_{i}=\sum W_{i j} Y_{j}
$$

Calculate the error between obtained output at the output layer and the target output value. Then based upon the error value, change the weights using the backpropagation algorithm and repeat the process until the error becomes zero.

\section{Simulation Results and Discussion}

The simulation results of the proposed RBFNANN controlled HEV are discussed in this section. A complete simulation is carried out by using a MATLAB/Simulink environment. The output energy from the solar panel and fuel cell stack will be integrated and the output of the hybrid system is generating a voltage of around $48 \mathrm{~V}$. Figure 9 shows the voltage, current, and power generated by the HGIBC converter. The available power from the hybrid energy source is tracked by using P\&O-FLC MPPT controller with respect to the various irradiance conditions such as $200 \mathrm{w} /$ $\mathrm{m}^{2}, 400 \mathrm{w} / \mathrm{m}^{2}, 600 \mathrm{w} / \mathrm{m}^{2}, 800 \mathrm{w} / \mathrm{m}^{2}$ and $1000 \mathrm{w} /$ $\mathrm{m}^{2}$. The integrated output of the solar fuel cell hybrid system has been directed to high gain interleaved boost converter whose switches are controlled with fuzzy controller. Figure 9 shows the voltage and current generated by the solar panel at an irradiance of $1000 \mathrm{w} / \mathrm{m}^{2}$. The energy is harvested from the hybrid system with the help of P\&O-FLC MPPT method. The output voltage of the interleaved boost converter is $370 \mathrm{~V}$ and it is connected to the input of the three-phase inverter.
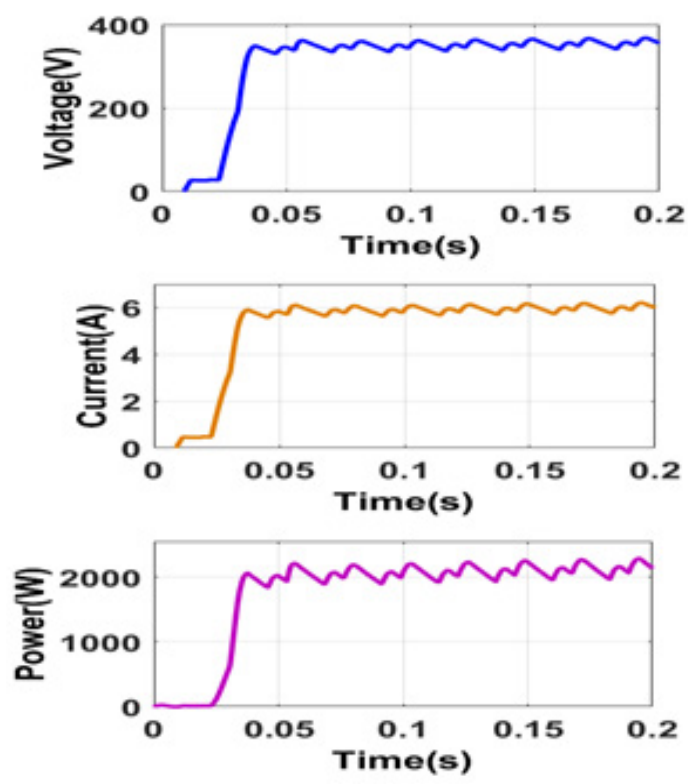

Figure 9. HGIBC Output Voltage (V), Current (A), and Power (W)

\subsection{PI controller}

The BLDC motor has been controlled through the sensorless speed control and the sensorless speed control has been implemented with PI controller and also with FLC controller. Figure 10 shows the voltage generated by the inverter with PI controller based speed control technique.
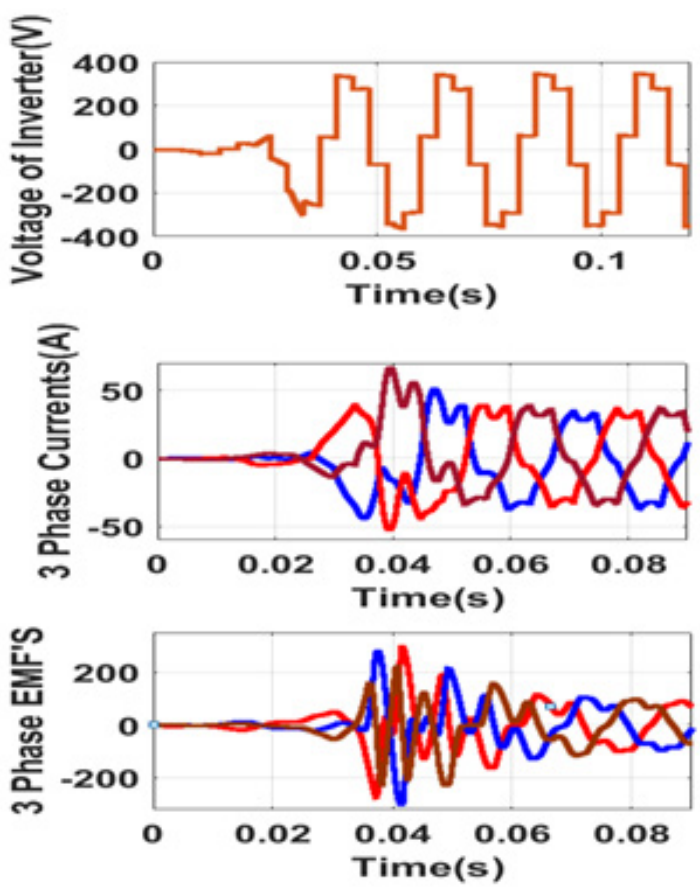

Figure 10. PI Controller - Voltage of Inverter (V), 3-Phase Currents (A) and 3-Phase EMFs (V)

The three-phase voltage generated by the inverter has been directed to a brushless DC motor whose 
three-phase currents and three-phase EMFs are also shown in Figure 10. Figure 11 shows the speed and torque generated by the BLDC motor driven by PI controller based speed control technique.
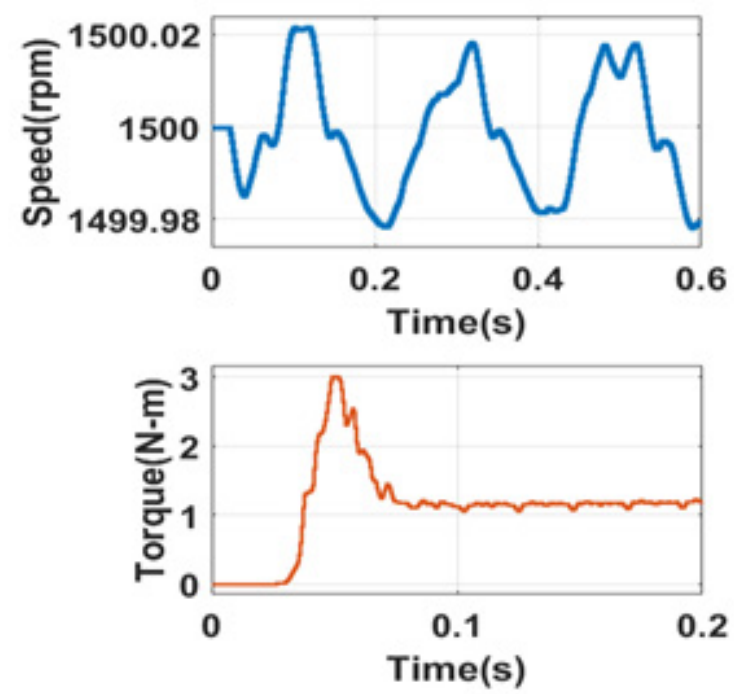

Figure 11. PI Controller - Speed and Torque $(\mathrm{N} \cdot \mathrm{m})$

\subsection{RBFN-ANN Controller}

The BLDC motor has been controlled with the sensorless speed control and also the sensorless speed control has been implemented with RBFNANN along with the FLC-MPPT controller. Figure 12 shows the voltage, current and EMF of the inverter with FLC-MPPT based control strategy.

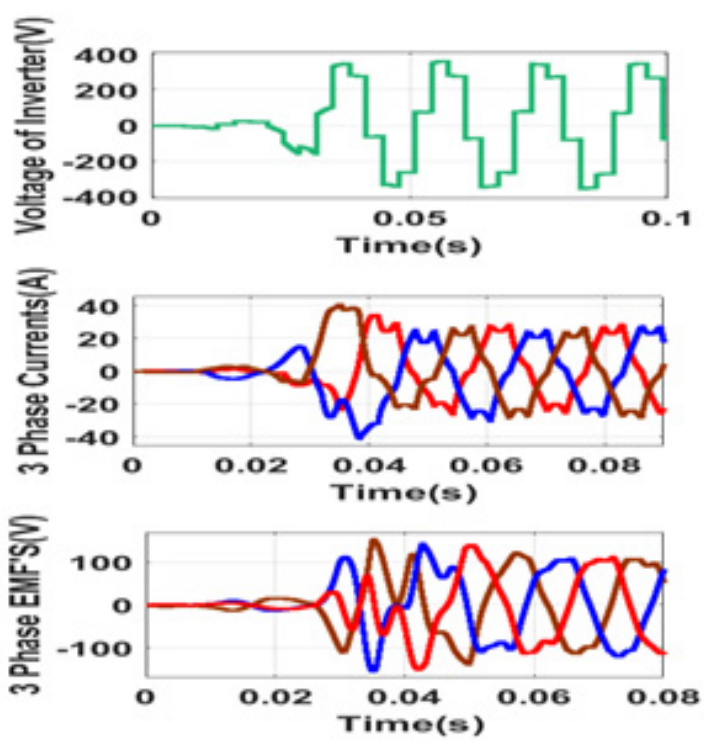

Figure 12. RBFN-ANN Controller - Voltage of Inverter (V), 3-Phase Currents (A) and 3-Phase EMFs (V)

As the motor is being controlled by the sensorless control and the speed and torque are controlled by using RBFN-ANN controller. Figure 13 shows the speed and torque generated by the BLDC motor driven by RBFN-ANN controller based speed control technique.
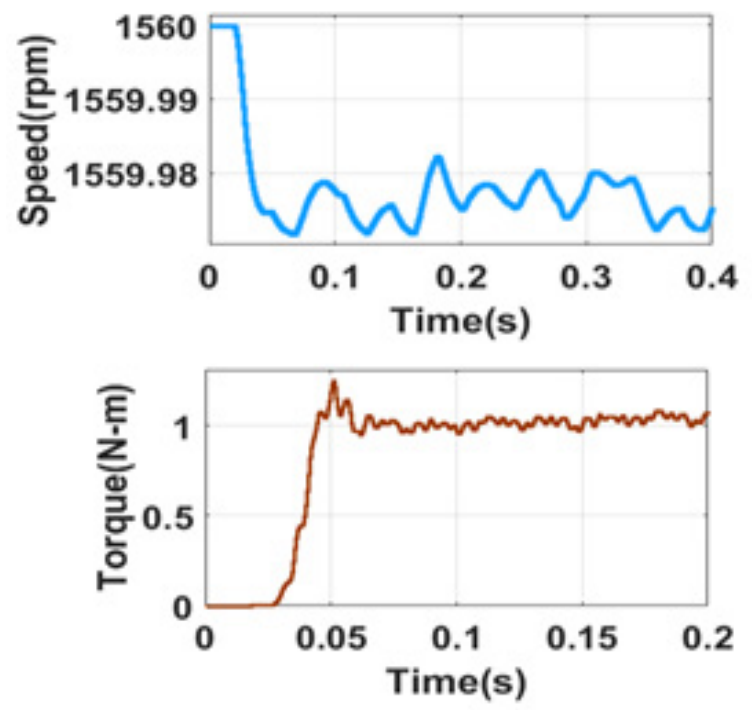

Figure 13. RBFN-ANN controller-Speed and Torque $(\mathrm{N} \cdot \mathrm{m})$

The speed of the integrated system is controlled by using both PI and RBFN-ANN controllers whose comparative performance has been tested for constant load torque in which case the RBFNANN controller shows a better performance than the PI controller in terms of speed and also torque ripple content.

\subsection{Comparative and Performance Analysis}

The performance analysis of the proposed RBFN ANN-based HEV is discussed in this subsection. The design of the electric vehicle with the utilization of renewable energy sources like solar energy combined with fuel cell energy was already presented in this paper.

Figures 14 and 15 show the speed and torque generated by the PI controller and RBFN-ANN controller under constant load torque conditions, where RBFN-ANN controller shows a better performance than the PI controller in terms of speed and also torque ripple content.

The comparative performance of the PI and RBFN-ANN controllers is also tested for variable load torque in which case the RBFN-ANN controller shows a better performance than the PI controller in terms of speed and torque ripple content. Figures 16 and 17 show the speed and torque generated by the PI controller and RBFN- 
ANN controller where the RBFN-ANN controller shows a better performance than the PI controller in terms of speed and ripple content while the PI controller provides a larger peak overshoot with a higher response time.
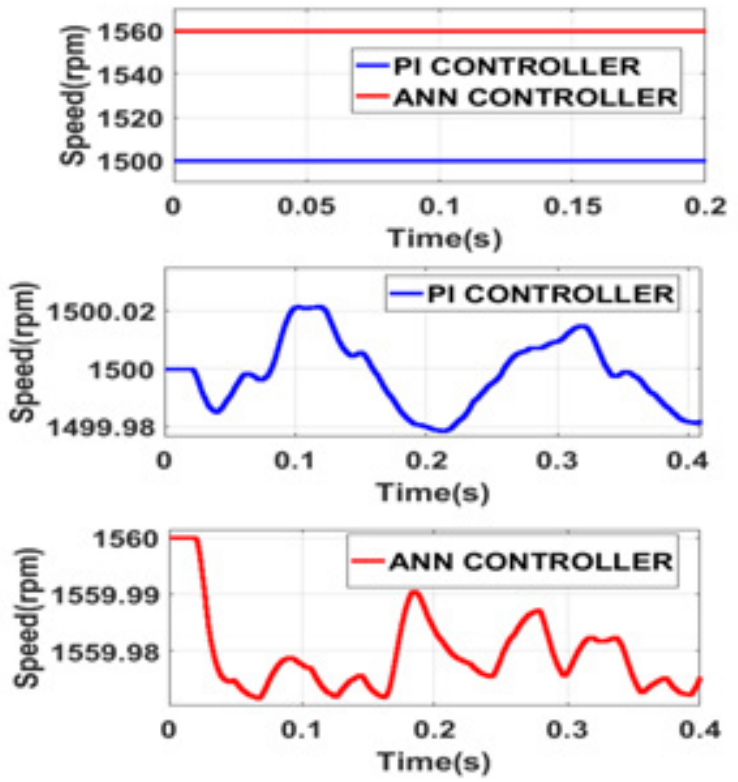

Figure 14. Speed Response - PI \& RBFN-ANN Controllers - constant load torque

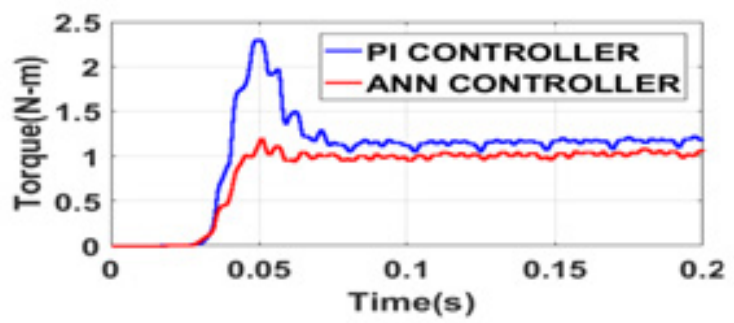

Figure 15. Torque Response - PI \& RBFN-ANN Controllers - constant load torque $(\mathrm{N} \cdot \mathrm{m})$
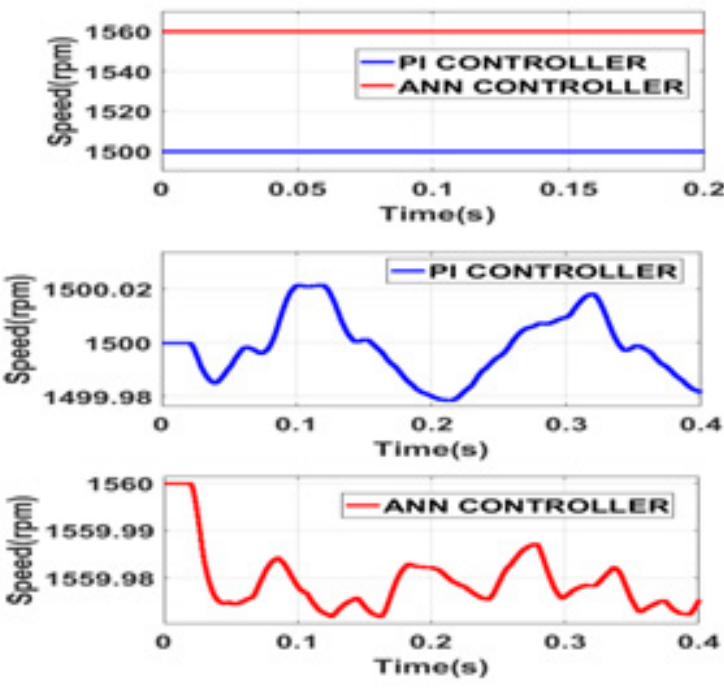

Figure 16. Speed Response - PI \& RBFN-ANN Controllers - variable load torque $(\mathrm{N} \cdot \mathrm{m})$

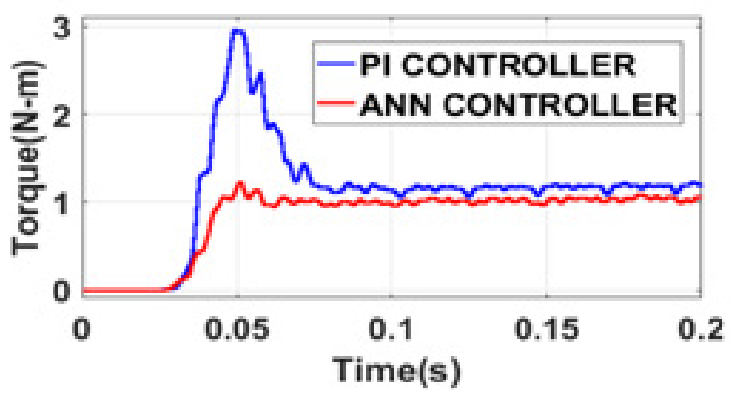

Figure 17. Torque Response- PI \& RBFN-ANN Controllers - variable load torque $(\mathrm{N} \cdot \mathrm{m})$

The comparative performance of the PI and RBFN-ANN controllers is also given for no load torque conditions. The RBFN-ANN controller shows a better performance than the PI controller in terms of torque ripple and speed. Figures 18 and 19 show the speed and torque ripple generated by the PI controller and RBFN-ANN controller where the RBFN-ANN controller shows a better performance than the PI controller in terms of torque ripple and speed response while the PI controller provides a higher peak overshoot with higher response time.
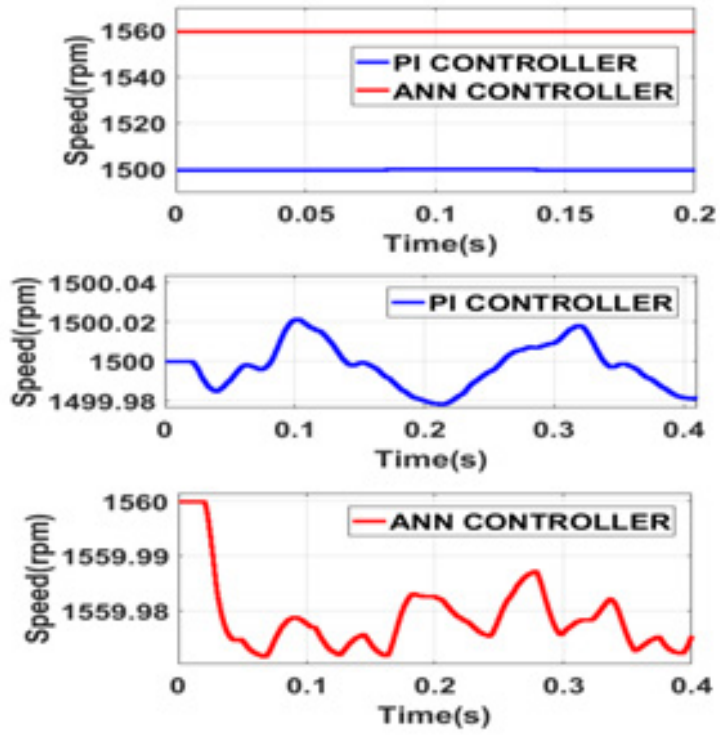

Figure 18. Speed Response - PI \& RBFN-ANN Controllers -no load torque $(\mathrm{N} \cdot \mathrm{m})$

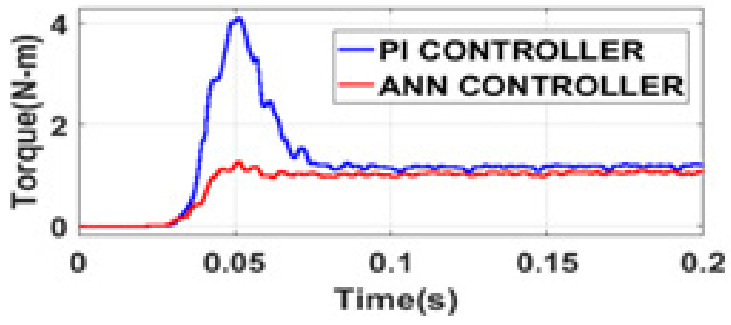

Figure 19. Torque Response - PI \& RBFN-ANN Controllers - no load torque $(\mathrm{N} \cdot \mathrm{m})$ 
Table 1 shows the comparative result summary for the PI and RBFN-ANN controllers with no load torque and from the Table1, it can be concluded that the speed control with RBFNANN controller shows a better performance in terms of response time, overshoot and efficiency. In this case the ripple content is higher for the PI controller (" 0.15 ") than for the RBFN-ANN controller ("0.1").

Table 1. Summary: PI and RBFN-ANN controller with no load torque

\begin{tabular}{|c|c|c|c|}
\hline Performance & Parameters & PI & ANN \\
\hline \multirow{2}{*}{ Dynamic } & $\begin{array}{c}\text { Response time } \\
(\mathrm{ms})\end{array}$ & 0.1 & 0.05 \\
\cline { 2 - 4 } & Overshoot (\%) & $80 \%$ & $2 \%$ \\
\hline Static & Ripple $(\mathrm{N} \cdot \mathrm{m})$ & 0.15 & 0.1 \\
\hline \multirow{2}{*}{ Efficiency } & $\begin{array}{c}\text { Output speed } \\
\text { average value } \\
(\mathrm{rpm})\end{array}$ & 1500.01 & 1559.9 \\
\cline { 2 - 4 } & $\begin{array}{c}\text { Output torque } \\
\text { average value } \\
(\mathrm{N} \cdot \mathrm{m})\end{array}$ & 1.18 & 1.05 \\
\hline
\end{tabular}

Table 2 shows the comparative result summary for the PI and RBFN-ANN controllers with constant load torque and from the Table 2, it can be concluded that RBFN-ANN controller shows a better performance in terms of response time, overshoot, ripple content of the torque and efficiency.

Table 2. Summary: PI and RBFN-ANN controller with constant load torque

\begin{tabular}{|c|c|c|c|}
\hline Performance & Parameters & PI & ANN \\
\hline \multirow{2}{*}{ Dynamic } & $\begin{array}{c}\text { Response time } \\
(\mathrm{ms})\end{array}$ & 0.077 & 0.075 \\
\cline { 2 - 4 } & Overshoot $(\%)$ & $30 \%$ & $10 \%$ \\
\hline Static & Ripple $(\mathrm{N} \cdot \mathrm{m})$ & 0.11 & 0.175 \\
\hline \multirow{2}{*}{ Efficiency } & $\begin{array}{c}\text { Output speed } \\
\text { average value } \\
(\mathrm{rpm})\end{array}$ & 1500.02 & 1559.99 \\
\cline { 2 - 4 } & $\begin{array}{c}\text { Output torque } \\
\text { average value } \\
(\mathrm{N} \cdot \mathrm{m})\end{array}$ & 1.13 & 1.21 \\
\hline
\end{tabular}

Table 3 shows the comparative result summary for the PI and RBFN-ANN controllers with variable load torque and from the table it can be concluded that the RBFN-ANN controller shows a better performance in terms of response time, overshoot, ripple content of the torque and efficiency. Table 4 provides a comparison between the proposed sensorless speed control technique and other existing speed control techniques where the proposed method gives better performance in terms of torque ripple and speed.

Table 3. Summary: PI and RBFN-ANN controller with variable load torque

\begin{tabular}{|c|c|c|c|}
\hline Performance & Parameters & PI & $\begin{array}{c}\text { RBFN- } \\
\text { ANN }\end{array}$ \\
\hline \multirow{2}{*}{ Dynamic } & $\begin{array}{c}\text { Response time } \\
(\mathrm{ms})\end{array}$ & 0.073 & 0.055 \\
\cline { 2 - 4 } Static & Overshoot (\%) & $20 \%$ & $6 \%$ \\
\hline \multirow{2}{*}{ Efficiency } & $\begin{array}{c}\text { Ripple }(\mathrm{N} \cdot \mathrm{m}) \\
\text { Output speed } \\
\text { average value } \\
\text { (rpm) }\end{array}$ & 0.12 & 0.176 \\
\cline { 2 - 4 } & $\begin{array}{c}\text { Output torque } \\
\text { average value } \\
\text { (N·m) }\end{array}$ & 1.14 & 1.25 \\
\hline
\end{tabular}

Table 4. Summary: Sensor versus Sensorless control

\begin{tabular}{|c|c|c|}
\hline Performance & $\begin{array}{c}\text { Torque ripple } \\
(\mathrm{N} \cdot \mathrm{m})\end{array}$ & $\begin{array}{c}\text { Speed ripple } \\
(\mathrm{rpm})\end{array}$ \\
\hline (Srikanth et.al., 2020) & 0.1 & 10 \\
\hline $\begin{array}{c}\text { (Ramírez-Cárdenas \& } \\
\text { Trujillo-Romero, 2020) }\end{array}$ & 0.14 & 12 \\
\hline $\begin{array}{c}\text { (Muralidhar \& Aranasi, } \\
\text { 2014) }\end{array}$ & 0.16 & 13 \\
\hline (Mondal et al., 2015) & 1.12 & 9 \\
\hline Proposed model & 0.055 & 0.176 \\
\hline
\end{tabular}

\section{Conclusion}

In this paper a Radial Basis Function Network controlled sensorless HEV using BLDC is presented. In this context, hybrid energy sources are designed for supplying electrical energy to the HEV. This involves the design of an MPPT system using FLC to track the maximum power from hybrid energy sources under various weather conditions. The RBFN-ANN shows a better performance than the PI controller by $30 \%$ with respect to the peak overshoot in case of no load condition. In the case of variable load torque condition. The RBFN-ANN also has a $18 \%$ better performance than the PI controller. At last, the RBFN-ANN shows a $10 \%$ better performance than the PI controller in the case of constant load condition. The entire analysis has been verified through the MATLAB/Simulink environment. 


\section{REFERENCES}

Darcy Gnana Jegha, A., Subathra, M. S. P., Manoj Kumar, N., Subramaniam, U. \& Padmanaban, S. (2020). A high gain DC-DC converter with grey wolf optimizer based MPPT algorithm for PV fed BLDC motor drive, Applied Sciences, 10(8), 2797.

El-Samahy, A. A. \& Shamseldin, M. A. (2018). Brushless DC motor tracking control using self-tuning fuzzy PID control and model reference adaptive control, Ain Shams Engineering Journal, 9(3), 341-352.

Gamazo-Real, J. C., Vázquez-Sánchez, E. \& GómezGil, J. (2010). Position and speed control of brushless DC motors using sensorless techniques and application trends, Sensors, 10(7), 6901-6947.

He, Y., Zheng, S. \& Fang, J. (2017). Start-up current adaptive control for sensorless high-speed brushless DC motors based on inverse system method and internal mode controller, Chinese Journal of Aeronautics, 30(1), 358-367.

Jafarboland, M. \& Silabi, M. H. R. (2019). New sensorless commutation method for BLDC motors based on the line-to-line flux linkage theory, IET Electric Power Applications, 13(6), 703-711.

Jyotheeswara Reddy, K. \& Sudhakar, N. (2018). High voltage gain interleaved boost converter with neural network based MPPT controller for fuel cell based electric vehicle applications, IEEE Access, 6, 3899-3908.

Kawamoto, R., Mochizuki, H., Moriguchi, Y., Nakano, T., Motohashi, M., Sakai, Y. \& Inaba, A. (2019). Estimation of CO2 Emissions of internal combustion engine vehicle and battery electric vehicle using LCA, Sustainability, 11(9), 2690.

Kommula, B. N. \& Kota, V. R. (2020). Direct instantaneous torque control of Brushless DC motor using firefly Algorithm based fractional order PID controller, Journal of King Saud UniversityEngineering Sciences, 32(2), 133-140.

Meng, X., Rozycki, P., Qiao, J.-F. \& Wilamowski, B. M. (2017). Nonlinear system modeling using RBF networks for industrial application, IEEE Transactions on Industrial Informatics, 14(3), 931-940.

Mondal, S., Mitra,A., Chowdhury,D.\& Chattopadhyay, M. (2015). A new approach of sensorless control methodology for achieving ideal characteristics of brushless DC motor using MATLAB/Simulink. In Proceedings of the 2015 Third International Conference on Computer, Communication, Control and Information Technology (C3IT) (pp. 1-4). IEEE.

Muralidhar, J. E. \& Aranasi, P. V. (2014). Torque ripple minimization \& closed loop speed control of BLDC motor with hysteresis current controller. In 2014 2nd International Conference on Devices, Circuits and Systems (ICDCS) (pp. 1-7). IEEE.

Park, J. S., Lee, K. D., Lee, S. G. \& Kim, W.-H. (2019). Unbalanced ZCP compensation method for position sensorless BLDC motor, IEEE Transactions on Power Electronics, 34(4), 3020-3024.

Parvaneh, M. H. \& Khorasani, P. G. (2020). A new hybrid method based on fuzzy logic for maximum power point tracking of photovoltaic systems, Energy Reports, 6, 1619-1632.

Pradeep, M. D., Ramesh, S. M. \& Gomathy, B. (2021). An Optimized PV based Plug-in Hybrid Electric Vehicle Charging Station Using Fuzzy-PI Controller Logic, Studies in Informatics and Control, 30(2), 5566. DOI: $10.24846 / v 30 i 2 y 202105$

Srikanth, R., Venkatesan, M. \& Subba Rao, M. (2020). Design and performance evaluation of PID, Fuzzy logic and ANN controllers based MPPTs for hybrid electric vehicle applications, International Journal of Ambient Energy, 41, 1-15.

Tawalbeh, M., Al-Othman, A., Kafiah, F., Abdelsalam, E.,Almomani,F.\&Alkasrawi,M.(2021). Environmental impacts of solar photovoltaic systems: A critical review of recent progress and future outlook, Science of The Total Environment, 759, 143528.

Zandi, Z. \& Mazinan, A. H. (2019). Maximum power point tracking of the solar power plants in shadow mode through artificial neural network, Complex \& Intelligent Systems, 5(3), 315-330.

Zarrad, O., Hajjaji, M. A. \& Mansouri, M. N. (2019). Hardware implementation of hybrid wind-solar energy system for pumping water based on artificial neural network controller, Studies in Informatics and Control, 28(1), 35-44. DOI: 10.24846/v28i1y201904 